\title{
Cestode and nematode larvae of hygienic-sanitary importance parasitizing Percophis brasiliensis (Actinopterygii) collected from fish markets of the municipality of Niterói, RJ, Brazil
}

\author{
Jéssica Botti DINIZ1 (D), Marcelo KNOFF²* (D), Michelle Cristie Gonçalves da FONSECA² (D), \\ Delir Corrêa GOMES ${ }^{2}$ (D), Sergio Carmona de São CLEMENTE ${ }^{1 \dagger}$
}

\begin{abstract}
Percophis brasiliensis is a fish species appreciated as a fried appetizer at beachside kiosks of Niterói, state of Rio de Janeiro, Brazil. The constant presence of helminth larvae in the viscera and serosa of individuals of the species has been the subject of complaints among local fish traders because of economic losses due to their repugnant aspect. Considering their hygienic-sanitary importance and significance for collective health, the presence of helminth larvae was investigated in 64 individual fish of P. brasiliensis purchased from Niterói fish markets in 2019. Cestodes, identified as larvae of Grillotia carvajalregorum, were found parasitizing the serosa of the stomach, mesentery and abdominal cavity. Nematodes, identified as third-instar larvae of Contracaecum sp., Terranova sp., Hysterothylacium deardorffoverstreetorum, H. fortalezae and Raphidascaris sp., were found parasitizing the stomach, intestine, liver, gonads, stomach serosa, mesentery and abdominal cavity. The highest parasitic indices were for G. carvajalregorum and H. deardorffoverstreetorum, with prevalences of $100 \%$ and $81.25 \%$, mean intensities of 8.05 and 8.13, mean abundances of 8.05 and 6.61 and infection ranges of 1-131 and 1-42 specimens per host, respectively. Considerations about the zoonotic potential and hygienic-sanitary significance of these parasites are presented in order to increase food safety for consumers.
\end{abstract}

Keywords: Percophis brasiliensis; Anisakidae; Raphidascarididae; Trypanorhyncha; fish sanitary inspection.

Practical Application: cestode and nematode larvae with potential to cause anisakidosis in humans.

\section{Introduction}

The fish species Percophis brasiliensis Quoy \& Gaimard, 1825, or Brazilian flathead, occurs in the southwest of the Atlantic Ocean off the South American coast from state of Rio de Janeiro, Brazil, to Argentina. It has a demersal habit and feeds on small fish, cephalopods and crustaceans (Bernardes et al., 2005). It is of medium to small size with a plump and longitudinal anatomy that facilitates the preparation of dishes that are served and enjoyed as a snack. The species is highly appreciated by consumers due to its tasty and soft white meat and its low cost compared to mullets and sardines.

The maintenance of hygienic-sanitary conditions in fish markets of the municipality of Niterói, Rio de Janeiro, Brazil, has been a concern for municipal health surveillance. For example, larvae of trypanorhynch cestodes and anisakid nematodes have been found currently in the abdominal cavity and viscera serosa of $P$. brasiliensis at some of the fish markets, which cause a repugnant appearance resulting losses in sales. Furthermore, oriental cuisine and the consumption of raw fish have aroused a popular taste in western countries, increasing exposure to the risk of accidental infection by fish parasites (Broglia \& Kapel, 2011).
Cestodes of the order Trypanorhyncha are cosmopolitan parasites of marine fish and invertebrates, especially in tropical and subtropical regions. Adults inhabit the gastrointestinal tract of elasmobranchs while larvae occur in the celomic cavity, visceral serosa and musculature of cephalopod, crustacean and teleost intermediate hosts (Palm, 2004). Parasitism of Brazilian fish by trypanorhynch larvae has been reported in papers on taxonomy, parasite ecology and hygienic-sanitary conditions (São Clemente et al., 1997; Felizardo et al., 2010, Oliveira et al., 2019). Trypanorhynch larvae acquire significance due to their repugnant aspect, especially when present as massive infections in musculature and organs, which can make commercialization infeasible due to sanitary inspection and/or consumer rejection, thus resulting in economic losses (Oliveira et al., 2019). The allergenic potential of some of these cestode species has been studied in tests carried out with murine models (Mattos et al., 2015).

Nematodes of the families Anisakidae and Raphidascarididae are commonly found in marine fish acting as intermediate hosts while definitive hosts can be aquatic mammals or fish-eating birds. Humans become accidental hosts by eating infected raw or undercooked fish (Anderson, 2000). Anisakid and 
raphidascaridid larvae have been reported parasitizing several marine fish in Brazil (Felizardo et al., 2009; Fonseca et al., 2016). Audicana and Kennedy (2008) reported the zoonotic potential of anisakid nematodes because they can cause allergic and/or anaphylactic reactions and gastrointestinal problems. Species of the genera Anisakis, Pseudoterranova and Contracaecum have been highlighted, with A. simplex (Rudolphi, 1809) and P. decipiens (Krabbe, 1878) accounting for most cases. Yagi et al. (1996) reported a case of human intestinal infection by the raphidascaridid Hysterothylacium aduncum (Rudolphi, 1802). The first clinical case of anisakidosis in Brazil reported the presence of an Anisakis-like larva in the stomach of an adult man (Cruz et al., 2010). Studies using a murine model have reported the allergenic potential of $H$. deardorffoverestreetorum Knoff, Felizardo, Iñiguez, Maldonado Jr, Torres, Pinto \& Gomes, 2012 and C. multipapillatum (Drasche, 1882) Baylis, 1920 (Ribeiro et al., 2017; Fontenelle et al., 2018).

According to the Brazilian legislation that deals with fish and their derivative products, any fish with a repugnant appearance, as in any musculature possessing massive parasite infection, is considered improper for consumption, whether or not it may affect the health of consumers (Brasil, 2017).

Trypanorhynch cestodes and anisakid and raphidascaridid nematodes parasitizing $P$. brasiliensis have been reported in studies about the composition and structure of parasite assemblages in Brazil, Uruguay and Argentina. These helminth larvae were recognized as biological markers as host stock descriptors and as biogeographic indicators (Braicovich \& Timi, 2008, 2010; Braicovich et al., 2016, 2017).

The present investigation aimed to: (1) identify the species of trypanorhynch cestode plerocerci and of third-stage anisakid and raphidascaridid nematode larvae parasitizing $P$. brasiliensis acquired in the markets of the municipality of Niterói, state of Rio de Janeiro, by means of morphological and morphometric analyses using optical microscopy of specimens retrieved from the site of infection; (2) present their parasitic indexes and infection sites, considering their zoonotic threat; and (3) demonstrate the hygienic-sanitary significance of these parasites to collective human health, providing baseline data for subsequent investigations.

\section{Material and methods}

Sixty-four specimens of Percophis brasiliensis, the Brazilian flathead (32-55 cm of total length), were purchased fish markets of the municipality of Niterói, state of Rio de Janeiro, Brazil, between February and April 2019. Fish were transported on ice to the laboratory where they were identified according to Bernardes et al. (2005). Necropsy was performed and the internal organs and musculature were examined. Found cestode blastocysts were removed from the serosa and organs, transferred to Petri dishes with distilled water and the plerocerci cysts opened (under a stereomicroscope using sharp needles) to release the larvae, which were then refrigerated for at least $24 \mathrm{~h}$ to permit relaxation of scolices and tentacular extroversion. All larvae were fixed in cold AFA (ethanol, formalin, and acetic acid), stained with Langeron's carmine, dehydrated in an increasing ethanol series, clarified in beechwood creosote and preserved as whole mounts in Canada balsam. Found nematode larvae were placed in Petri dishes with $0.65 \% \mathrm{NaCl}$ solution, fixed in $\mathrm{AFA}$ at $60^{\circ} \mathrm{C}$, preserved in $70 \%$ ethanol and later clarified with Amman's lactophenol (Knoff \& Gomes, 2012). Taxonomic classification of cestodes and nematodes followed Caira \& Jensen (2017) and De Ley \& Blaxter (2002), respectively. Species identification of cestodes followed Menoret \& Ivanov (2009), while identification of nematodes followed Felizardo et al. (2009), Knoff et al. (2012) and Fontenelle et al. (2015). Cestode and nematode larvae were observed using an Olympus BX-41 brightfield microscope and measurements were made in millimeters $(\mathrm{mm})$, with means being provided in parentheses. Parasitic indices were calculated following Bush et al. (1997). Representative specimens of each parasite species were deposited in the Coleção Helmintológica do Instituto Oswaldo Cruz (CHIOC), Rio de Janeiro, RJ, Brazil.

\section{Results}

All 64 analyzed specimens of P. brasiliensis (100\%) were found parasitized by trypanorhynch cestode plerocerci (total 515) and $53(82.8 \%)$ by third-instar $\left(\mathrm{L}_{3}\right.$; total 475$)$ anisakid (5) and raphidascaridid (470) nematode larvae. Most trypanorhynch and nematode larvae were alive and showed high motility. Figure 1 shows one of the collected fish, with the abdominal cavity opened, parasitized with massive infections of a large
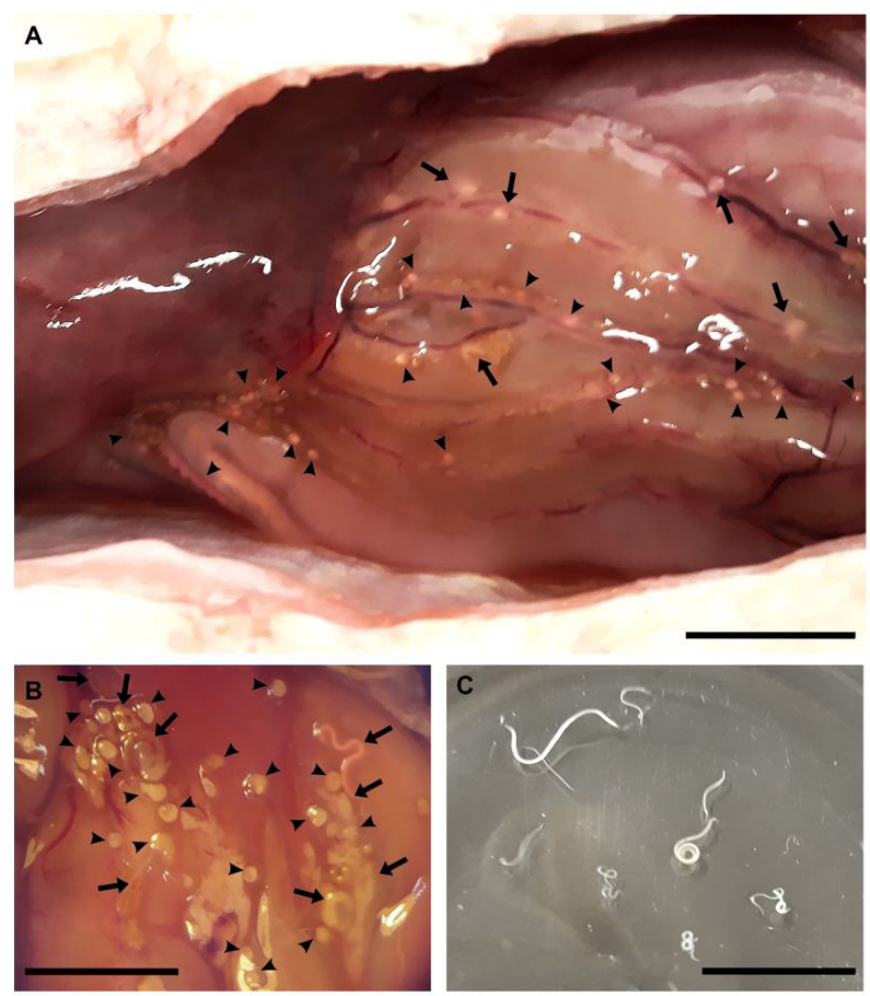

Figure 1. (A) Percophis brasiliensis with abdominal cavity opened showing, visible to the naked eye, helminth parasites on viscera serosa: cestode blastocysts (arrowhead) and nematode larvae (arrows); (B) Detail showing piriform cestode blastocysts (arrowhead) and free and encapsulated nematode larvae (arrows); C. Nematode larvae after removal from viscera serosa. Scale bars: $(A)$ and $(C)=1 \mathrm{~cm}$, and (B) $=0.5 \mathrm{~cm}$. 
number of cestode blastocysts and nematode third-instar larvae in viscera serosa.

The taxonomic identification of the collected helminths follows.

Platyhelminthes Minot, 1876, Rhabditophora Ehlers, 1985, Neodermata Ehlers, 1985, Cestoidea Rudolphi, 1808, Eucestoda Southwell, 1930, Trypanorhyncha Diesing, 1863, Trypanoselachoidea sensu Beveridge, Haseli, Ivanov, Menoret \& Schaeffner, 2017, Lacistorhynchoidea Guiart, 1927, Grillotiidae Dollfus, 1969

\section{Grillotia Guiart, 1927}

Grillotia (Christianella) carvajalregorum (Carvajal \& Rego, 1983) Menoret \& Ivanov, 2009. Figures 2A-C.

Main characteristics observed in 20 plerocerci from the 515 blastocysts collected. Plerocercus with piriform blastocyst. Plerocerci $0.75-2.37$ (1.34) long x 0.17-0.46 (0.26) wide at pars bothrialis and $0.06-0.027(0.13)$ wide at pars vaginalis. Scolex elongate, acraspedote. Two sub-cordiform bothria, each with slight indentation in posterior margin. Surfaces of scolex and pars bothrialis covered by microtriches. Pars bothrialis long, sheaths sinuous. Pars vaginalis elongate, sheaths coiled at bulbs insertion proximal portion and sinuous at distal portion. Bulbs elongate. Retractor muscle originates at posterior third of bulbs. Pars postbulbosa $1 / 4$ of body length. Tentacules elongate and tapered, without basal swelling. Armature heteracanthous,
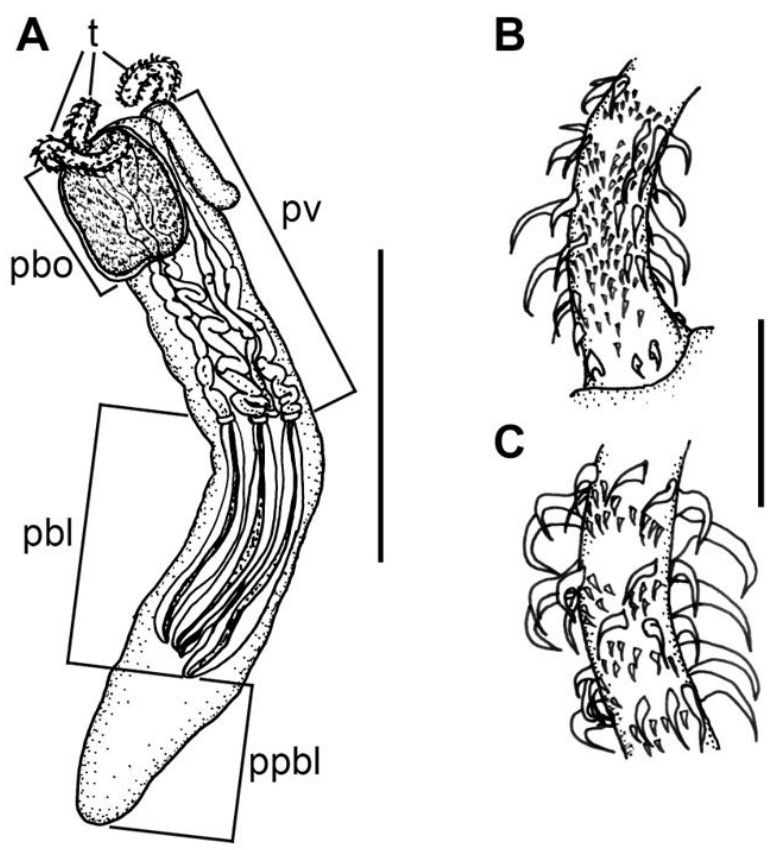

Figure 2. Grillotia carvajalregorum. (A) Entire plerocercus. Tentacles $(\mathrm{t})$, pars bothrialis (pbo), pars vaginalis (pv), pars bulbosa (pbl), pars postbulbosa (ppbl); (B) Detail of the arrangement of hooks on the external surface of the basal armature tentacle; (C) Detail of the arrangement of hooks on the external surface of the metabasal armature tentacle. Scale bars: (A) $0.40 \mathrm{~mm}$ and $(B-C)=0.05 \mathrm{~mm}$. atypical, hooks hollow and heteromorphous. Distinct basal armature consisting of 1-2 rows of uncinate hooks, continued by hooks showing different shapes and sizes; bothrial surface with uncinate hooks with recurved tips; antibothrial surface with elongate falcate hooks. Principal hooks begin at rows 2-3. Band of hooklets on external surface restricted to basal region of tentacle, extending from top of rows 1-2 of principal hooks up to rows 6-7; 6-7 hooklets in width, interrupted on metabasal region. Metabasal armature with ascending rows of four large hooks beginning on internal surface and terminating on external surface. Prominent space between hooks 1 and 1' on internal surface. Intercalary rows of 3-5 uncinate to spiniform hooks between hooks $2\left(2^{\prime}\right)-4\left(4^{\prime}\right)$.

Nematoda Potts, 1932, Cromadorea Inglis, 1983, Rhabdtida Chitwood, 1933, Ascaridomorpha De Ley \& Blaxter, 2002, Ascaridoidea Baird, 1853, Anisakidae Railliet \& Henry, 1912

Contracaecum Railliet \& Henry, 1912

Contracaecum sp. Figures 3A and 4A.

Main characteristics observed in one collected $\mathrm{L}_{3}$. Body 5.07 long $x 0.19$ wide. Cuticle with thin transverse striations, more evident on posterior end of body. Anterior end with one dorsal lip and two poorly developed ventrolateral lips. Six cephalic papillae present, one pair on dorsal lip and one pair on each ventrolateral lip. Boring tooth near oral aperture, between ventrolateral lips. Excretory pore opening beneath boring tooth. Ventriculus small and sub-spherical. Ventricular appendix nearly twice the length of intestinal caecum. Four sub-spherical rectal glands present. Tail conical and mucron absent.

\section{Terranova Leiper \& Atkinson, 1914}

Terranova sp. Figures 3B and 4B.

Main characteristics observed in four collected $\mathrm{L}_{3}$. Body 4.12-6.34 (5.13) long $x$ 0.16-0.20 (0.17) wide. Cuticle with thin transverse striations, more evident on posterior end of body. Anterior end with one dorsal lip and two poorly developed ventrolateral lips. Six cephalic papillae present, one pair on dorsal lip and one pair on each ventrolateral lip. Boring tooth below oral aperture, between ventrolateral lips. Excretory pore opening beneath boring tooth. Ventriculus longer than wide. Ventricular appendix absent. Intestinal caecum twice the length of ventriculus. Four sub-spherical rectal glands present. Tail conical and mucron absent.

\section{Raphidascarididae Hartwich, 1954}

\section{Hysterothylacium Ward \& Magath, 1917}

Hysterothylacium deardorffoverstreetorum Knoff, Felizardo, Iñiguez, Maldonado Jr, Torres, Pinto \& Gomes, 2012. Figures $3 \mathrm{C}$ and $4 \mathrm{C}$.

Main characteristics observed in fifteen of 423 collected $\mathrm{L}_{3}$. Body 3.70-11.74 (6.75) long x 0.17-0.38 (0.21) wide. Cuticle with lateral alae extending along the body with wedge-shaped support, devoid of basal extension. Anterior end with one dorsal and two poorly developed ventrolateral lips. Nine cephalic papillae present, two pairs on dorsal lip together with a large papilla and 

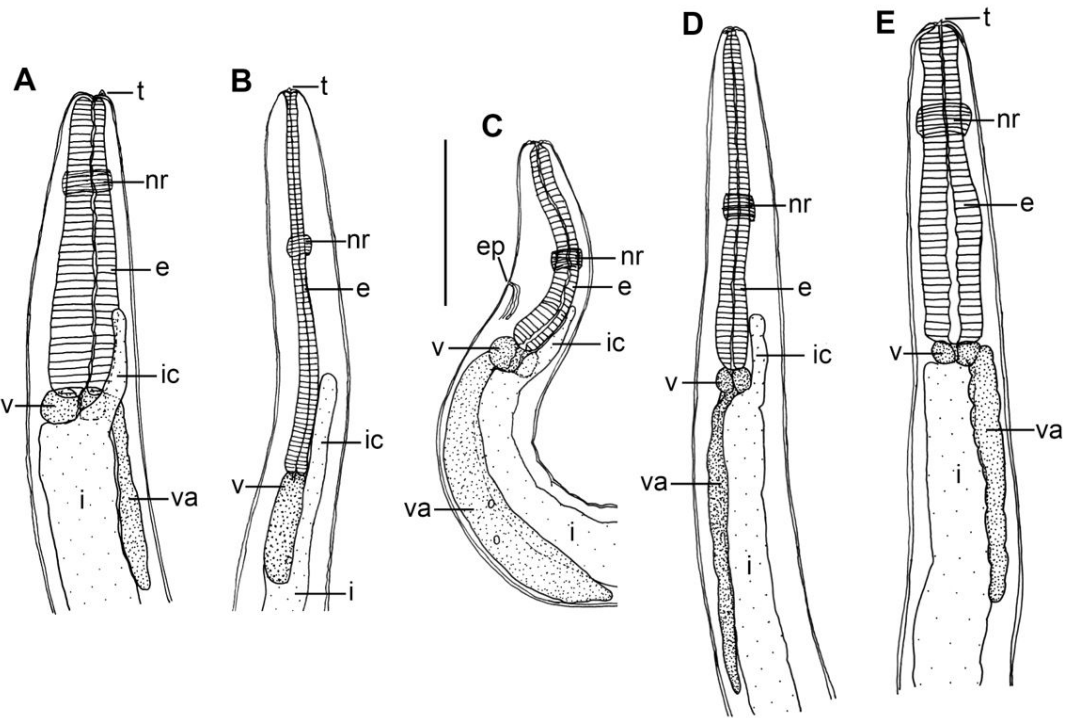

Figure 3. Anterior portions of third-instar anisakid and raphidascaridid nematode larvae collected from Percophis brasiliensis. (A) Contracaecum sp.; (B) Terranova sp.; (C) Hysterothylacium deardorffoverstreetorum; (D) H. fortalezae; (E) Raphidascaris sp. Larval tooth (t); nerve ring (nr); esophagus (e); intestinal cecum (ic); ventriculus (v); ventricular appendix (va); intestine (i); excretory pore (ep). Scale bar: $0.40 \mathrm{~mm}$.
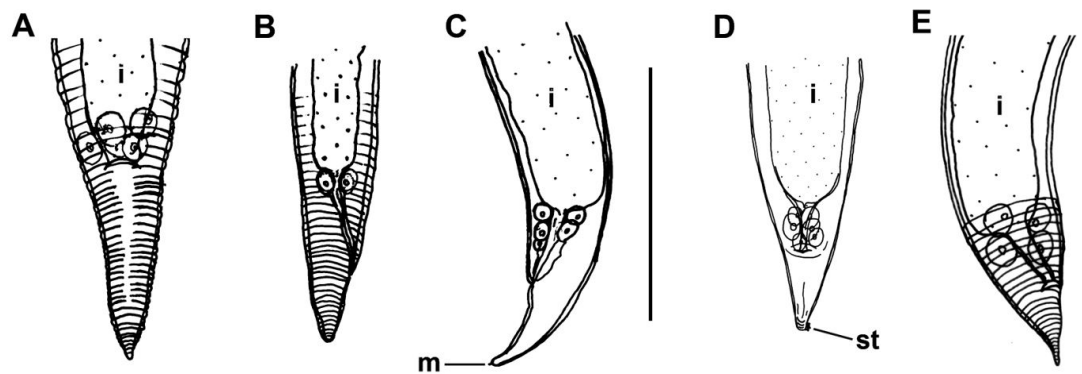

Figure 4. Posterior portions of third-instar anisakid and raphidascaridid nematode larvae. (A) Contracaecum sp.; (B) Terranova sp.; (C) Hysterothylacium deardorffoverstreetorum; (D). H. fortalezae; (E) Raphidascaris sp. Intestine (i), mucrom (m) and spinous tuft (st). Scale bar: 0.40 mm.

one pair on each ventrolateral lip. Boring tooth absent. Excretory pore opening beneath nerve ring. Ventriculus sub-spherical. Ventricular appendix longer than esophagus. Intestinal cecum present. Four to six sub-spherical rectal glands present. Tail conical with mucron.

Hysterothylacium fortalezae Klein, 1973. Figures 3D and 4D.

Main characteristics observed in fifteen of $46 \mathrm{~L}_{3}$ collected. Body 4.45-7.64 (6.33) long x 0.16-0.28 (0.21) wide. Cuticle almost smooth without evident transverse cuticular striations with lateral alae extending along the body, inconspicuous at anterior end. Anterior end with one dorsal and two poorly developed ventrolateral lips. Nine cephalic papillae present, two pairs on dorsal lip together with a large papilla and one pair on each ventrolateral lip. Boring tooth absent. Excretory pore opening beneath nerve ring. Ventriculus sub-spherical. Esophagus slightly larger than ventricular appendix. Intestinal cecum present. Six to four sub-spherical rectal glands present. Conical tail curved ventrally with tuft of six to eight spinous structures.

\section{Raphidascaris Railliet \& Henry, 1915}

Raphidascaris sp. Figures 3E and 4E.

Main characteristics observed in one collected $\mathrm{L}_{3}$. Body 6.85 long x 0.30 wide. Cuticle with thin transverse striations, more evident on posterior end. Anterior end with one dorsal and two poorly developed ventrolateral lips. Boring tooth near oral aperture, between ventrolateral lips. Excretory pore opening beneath nerve ring. Elongated esophagus with enlarged posterior end. Ventriculus wider than long. Ventricular appendix present. Intestinal cecum absent. Tail with pointed end with defined transverse striations.

Parasitic indices, infection ranges, infection sites and CHIOC deposit number for the collected cestodes and nematodes are shown in Table 1.

\section{Discussion}

Trypanorhynch cestodes and larval anisakid and raphidascaridid nematodes have previously been reported infecting P. brasiliensis in Brazil by Luque \& Poulin (2004), who identified the trypanorhynchs 
Table 1. Prevalence (P), intensity/mean intensity (I/MI), mean abundance (MA), range of infection (RI), infection site (IS) and CHIOC deposit number for trypanorhynch cestode plerocerci and third-stage anisakid and raphidascaridid nematode larvae collected from Percophis brasiliensis, marketed in the municipality of Niterói, state of Rio de Janeiro, between February and May 2019.

\begin{tabular}{|c|c|c|c|c|c|c|}
\hline Helminths & $\mathrm{P} \%$ & $\mathrm{I}^{\star} / \mathrm{MI}$ & MA & $\mathrm{RI}$ & IS & $\mathrm{CHIOC}$ \\
\hline \multicolumn{7}{|l|}{ Cestode } \\
\hline Grillotia carvajalregorum & 100 & 8.05 & 8.05 & $1-131$ & S, SS, M, AC & $\begin{array}{c}39275 a-b \\
39276,3927\end{array}$ \\
\hline \multicolumn{7}{|l|}{ Nematodes } \\
\hline Contracaecum sp. & 1.56 & 1 & 0.02 & - & $\mathrm{AC}$ & 38917 \\
\hline Terranova sp. & 4.68 & 1.33 & 0.06 & $1-2$ & $\mathrm{AC}, \mathrm{I}$ & 38918,38919 \\
\hline Hysterothylacium deardorffoverstreetorum & 81.25 & 8.13 & 6.61 & $1-42$ & $\begin{array}{c}\mathrm{AC}, \mathrm{SS}, \mathrm{S}, \mathrm{LI}, \\
\mathrm{IN}, \mathrm{GO}\end{array}$ & 38922,38923 \\
\hline H. fortalezae & 21.87 & 3.28 & 0.72 & $1-9$ & AC, IN & 38921 \\
\hline Raphidascaris sp. & 1.56 & $1^{*}$ & 0.02 & - & $\mathrm{AC}$ & 38920 \\
\hline
\end{tabular}

$\mathrm{AC}=$ abdominal cavity, $\mathrm{GO}=$ gonads, $\mathrm{I}=$ intestine, $\mathrm{LI}=$ liver, $\mathrm{M}=$ mesentery, $\mathrm{S}=$ stomach and $\mathrm{SS}=$ stomach serosa; ${ }^{\star}$ Only one host parasitized.

Nybelinia sp. and Grillotia sp.; the anisakids Anisakis sp., Contracaecum sp. and Terranova sp.; and the raphidascaridid Raphidascaris sp., from off the coast of Rio de Janeiro, Brazil. Luque \& Tavares (2006) presented details of the systematics, biology and importance for collective health of anisakid larvae, and a list with 60 species of marine boney fish collected from the state of Rio de Janeiro, where Anisakis sp., Contracaecum sp., Terranova sp., Hysterothylacium sp. and Raphidascaris sp. were parasitizing $P$. brasiliensis. In comparison with these previous reports, the present study did not observe larvae of Nybelynia sp. and Anisakis sp., and identified the species of Hysterothylacium as $H$. deardorffoverstreetorum and $H$. fortalezae, showing that the composition of these groups of larval helminths in this host was practically identical and corroborating the findings of the previous studies.

In South America, Braicovich \& Timi (2008) analyzed infra-communities of parasites of $P$. brasiliensis collected from four zones of localities of Uruguay and Argentina seas in ecoregions belonging to the Warm Temperate Southwestern Atlantic province. They found the trypanorhynch cestodes Grillotia sp., Callitetrarhynchus gracilis and Nybelinia sp.; the anisakids Anisakis simplex, Contracaecum sp. and Terranova sp.; and the raphidascaridids Hysterothylacium sp. and H. aduncum, which differ from the present study where only the parasite species G. carvajalregorum, Contracaecum sp., Terranova sp., $H$. deardorffoverstreetorum and $H$. fortalezae were found. Interestingly, the mean values for the parasitic indices reported by Braicovich \& Timi (2008), in the Uruguay and Argentina seas, for Grillotia sp., Contracaecum sp., Terranova sp. and. Hysterothylacium sp., with prevalences of $100 \%, 7.73 \%, 6.75 \%$ and $88.82 \%$, and mean abundances of $428.3,0.25,0.15$ and 48.7 , respectively, indicate that the cestode Grillotia sp. and the nematode Hysterothylacium sp. were dominant, as was found in the present study for G. carvajalregorum and $H$. deardorffoverstreetorum, and that the mean abundances of all the other reported species were lower. These differences and similarities are indicative of a biological marker for this host species in these different marine geographical ecoregions because the characteristics of local ecosystems and their trophic webs can determine not only the richness but also the abundance of larval helminths in fish hosts, as suggested by Braicovich \& Timi (2008).
Continuing with studies of the parasitic community of P. brasiliensis, Braicovich and Timi (2010) used part of their parasite data collected from the coast of Mar del Plata, Argentina (Braicovich \& Timi, 2008), and concluded the existence of seasonal stability in the parasite assemblages of the species, with a dominance of larval stages. They reported that larvae of the raphidascaridid nematode Hysterothylacium sp. and the trypanorhynch cestode $G$. carvajalregorum had the highest prevalences and mean abundances. These two species also had high prevalences in the present study but differed in having lower mean abundances. The authors also reported the species $H$. deardorffoverstreetorum and G. carvajalregorum to have prevalences of $93.2 \%, 100 \%$, mean abundances of 54.5 and 882.5 , and infection ranges of " 0 " -531 and 7-5,616, respectively. Both these species had high prevalences in the present study, although the number of parasites collected for each species was much higher for P. brasiliensis collected in Argentina, which suggests a difference between these two distinct marine ecoregions, i.e., Southeastern Brazil and Uruguay-Buenos Aires Shelf.

Braicovich et al. (2016) evaluated different fish traits as descriptors of patterns of cumulative parasite abundance and infra-community species richness, and identified the best tools for comparative studies of stock assessment using P. brasiliensis collected from Mar del Plata, Argentina, and three of its more common long-lived parasites - the nematode $H$. deardorffoverstreetorum, the cestode G. carvajalregorum, and the acanthocephalan Corynossoma australe - considered in others studies as suitable biological tags for stock assessment in the Southwestern Atlantic province (Braicovich \& Timi, 2008, 2010). Braicovich et al. (2017) subsequently studied the parasite composition of $P$. brasiliensis from nine localities, including the previous sampled localities from the Uruguay-Buenos Aires Shelf zoogeographic ecoregion (Braicovich \& Timi, 2008, 2010), and added the sampled localities of Cabo Frio (Southeastern Brazil), Rio Grande do Sul (Rio Grande), Villa Gessel, and Neocochea (Uruguay-Buenos Aires Shelf) of the Warm Temperate Southwestern Atlantic province. They concluded that larval parasites are suitable markers for stock assessment of $P$. brasiliensis, valuable tools as zoogeographical indicators, and are closely linked and similar between existing zoogeographical classifications of Spalding et al. (2007). Braicovich et al. (2017) observed that 
distributional patterns of parasites of this host indicate at least two discrete populations of these species, one in Southeastern Brazil and one in Rio Grande ecoregion waters, that are clearly differentiable from those previously identified in Uruguay-Buenos Aires Shelf ecoregion waters. They also reported for Cabo Frio parasitism by Terranova sp., Hysterothylacium sp., H. fortalezae, Raphidascaris acus, G. carvajalregorum, Callitetrarhynchus gracilis, Pterobothrium sp. and "Tentaculariidae" gen. sp. with prevalences of $5 \%, 87.5 \%, 12.5 \% 17.5 \%, 90 \%, 2.5 \%, 10 \%$ and $17.5 \%$ and mean abundances of $0.05,5.3,0.20,0.20,7.35,0.03$, 0.10 and 0.30 , respectively. When compared to the present study, these results reveal the occurrence of practically the same species of nematodes, with slight differences in the number of species of cestodes, but with the same pattern of dominance in the prevalence indices for the nematode Hysterothylacium sp. (=H. deardorffoverstreetorum) and the cestode G. carvajalregorum, which can be explained by the action of the same biotic and abiotic factors present in this marine ecoregion. This finding corroborates Spalding et al. (2007), who demonstrated that the marine ecoregions have relatively homogeneous species compositions that are clearly distinct from adjacent systems. Therefore, features observed among and within ecoregions can influence fish parasite communities and explain the differences in species assemblages of parasites of $P$. brasilensis from waters off Argentine and Uruguay (Braicovich \& Timi 2008, 2010; Braicovich et al., 2016, 2017), and from off the state of Rio de Janeiro, Brazil, observed in previous studies and reinforced by the present study.

Braicovich \& Timi (2008) reported that trypanorhynch metacestodes and third-stage nematode larvae found in P. brasiliensis were collected from the abdominal cavity, viscera and mesentery, which are the same infection sites found in the present study. Regarding the zoonotic potential and hygienic-sanitary significance of the helminths found in the present study, the blastocysts of trypanorhynch plerocerci were visible to the naked eye and were found mostly alive at high prevalences, with up to 131 parasites per host; although they were not been found in the musculature, they still give the consumer a repugnant aspect. In a study with a murine model, Mattos et al. (2015) warned about the ingestion of fish infected with species of trypanorhynch metacestodes as a possible cause of allergy in humans, and that future studies should be carried out in order to analyze this peculiarity. Furthermore, the hygienic-sanitary significance and collective health importance of the third-instar larvae of anisakid and raphidascaridid nematodes of the present study must to be emphasized. Although these larvae were found in the serosa of the viscera and in the abdominal cavity of host fish, the risk of ingesting these parasites can not be ruled out since most of the larvae were found alive and, thus, with the capacity for postmortem migration to the musculature, leading the possibility of human infection. The highest prevalence recorded in the present study was for $H$. deardorffoverstreetorum and the lowest for Contracaecum sp. and Raphidascaris sp. Larvae of the genus Contracaecum are known to have zoonotic potential and can even confer risk to the consumer when at low prevalences, since the ingestion of a single larva, living or dead, can trigger allergic reactions and/or disorders in the involved organs (Audicana \& Kennedy, 2008). Larvae of the genus Hysterothylacium should be given consideration as they have been reported to cause gastrointestinal discomfort in humans (Yagi et al., 1996). In addition, the allergenic potential of $H$. deardorffoverestreetorum and C. multipapillatum, collected from other Brazilian marine fish hosts, was recently demonstrated using a murine model (Ribeiro et al., 2017; Fontenelle et al., 2018). Preventive measures can reduce risks to consumer health, such as the evisceration of fish immediately after capture, which reduces the risk of migration by anisakid and raphidascaridid larvae to host musculature, as suggested by Knoff et al. (2007).

\section{Conclusions}

Beyond the repugnance, the presence of cestode plerocerci and third-instar nematode larvae is worrisome because of the potential risk of allergic reactions and anisakidosis for humans, thereby reinforcing the hygienic-sanitary significance of monitoring these parasites.

Intensification of fish-based food inspections and the implementation of health education programs are needed. Hazard Analysis and a Critical Control Points plan should be applied at all points of the production chain in order to eliminate, prevent or reduce risks, and ensure a safe and quality product, as proposed by Dias et al. (2011).

The occurrence of plerocerci of the trypanorhynch G. carvajalregorum and of larvae of the nematode $H$. deardorffoverstreetorum, both with high prevalences in the municipality of Niterói, reinforce the results of previous studies on the parasite fauna of $P$. brasiliensis indicating that these two helminth species are useful as biological markers to distinguish marine ecoregions.

\section{Acknowledgements}

The authors would like to thank Ricardo Baptista Schmidt from the Serviço de Produção de Imagens, IOC/Fiocruz for processing the figures, and to the Coordenação de Aperfeiçoamento de Pessoal de Nível Superior (CAPES) for partial financial support. This work was supported by a Conselho Nacional de Desenvolvimento Científico e Tecnológico (CNPq) fellowship S.C.S.C. (308048/2013-8).

\section{References}

Anderson, R. C. (2000). Nematode parasites of vertebrates. Their development and transmission (2nd ed.). London: CAB Publishing. http://dx.doi.org/10.1079/9780851994215.0000.

Audicana, M. T., \& Kennedy, M. W. (2008). Anisakis simplex: from obscure infections worm to inducer of immune hypersensitivity. Clinical Microbiology Reviews, 21(2), 360-379. http://dx.doi.org/10.1128/ CMR.00012-07. PMid:18400801.

Bernardes, R. A., Figueiredo, J. L., Rodrigues, A. R., Fischer, L. G., Vooren, C. M., Haimovici, M., \& Rossi-Wongstschwski, C. L. B. R. (2005). Peixes da zona econômica exclusive da região Sudeste-Sul do Brasil. São Paulo: Editora da Universidade de São Paulo.

Braicovich, P. E., \& Timi, J. T. (2008). Parasites as biological tags for stock discrimination of the Brazilian flathead Percophis brasiliensis in the south-west Atlantic. Journal of Fish Biology, 73(3), 557-571. http://dx.doi.org/10.1111/j.1095-8649.2008.01948.x. 
Braicovich, P. E., \& Timi, J. T. (2010). Seasonal stability in parasite assemblages of the Brazilian flathead, Percophis brasiliensis (Perciformes: Percophidae): predictable tools for stock identification. Folia Parasitologica, 57(3), 206-212. http://dx.doi.org/10.14411/ fp.2010.027. PMid:20941912.

Braicovich, P. E., Ieno, E. N., Sáez, M., Despos, J., \& Timi, J. T. (2016). Assessing the role of host traits as drivers of the abundance of long-lived parasites in fish-stock assessment studies. Journal of Fish Biology, 89(5), 2419-2433. http://dx.doi.org/10.1111/jfb.13127. PMid:27592692.

Braicovich, P. E., Pantoja, C., Pereira, A. N., Luque, J. L., \& Timi, J. T. (2017). Parasites of the Brazilian flathead Percophis brasiliensis reflect West Atlantic biogeographic regions. Parasitology, 144(2), 169-178. http://dx.doi.org/10.1017/S0031182016001050. PMid:27806734.

Brasil, Ministério da Agricultura, Pecuária e Abastecimento. (2017). Regulamenta a Lei ${ }^{\circ} 1.283$, de 18 de dezembro de 1950, e a Lei ${ }^{\circ}$ 7.889 , de 23 de novembro de 1989, que dispõem sobre a inspeção industrial e sanitária de produtos de origem animal (Decreto no 9.013 de 29 de março de 2017). Diário Oficial [da] República Federativa do Brasil.

Broglia, A., \& Kapel, C. (2011). Changing dietary habits in a changing world: Emerging drivers for the transmission of foodborne parasitic zoonoses. Veterinary Parasitology, 182(1), 2-13. http://dx.doi. org/10.1016/j.vetpar.2011.07.011. PMid:21835548.

Bush, A. O., Lafferty, K. D., Lotz, J. M., \& Shostak, A. W. (1997). Parasitology meets ecology on its own terms: Margolis et al. Revisited. The Journal of Parasitology, 83(4), 575-583. http://dx.doi. org/10.2307/3284227.

Caira, J. N., \& Jensen, K. (2017). Planetary biodiversity inventory (2008-2017): tapeworms from vertebrate bowels of the earth (Special Publication, No. 25). Lawrence: Natural History Museum, University of Kansas.

Cruz, A. R., Souto, P. C. S., Ferrari, C. K. B., Allegretti, S. M., \& ArraisSilva, W. W. (2010). Endoscopic imaging of the first clinical case of anisakidosis in Brazil. Revista Scientia Parasitologica, 11(2), 97-100.

De Ley, P., \& Blaxter, M. L. (2002). Systematic position and phylogeny. In Lee, D. L. (Ed.), The biology of nematodes (pp. 1-30). London: Taylor and Francis. http://dx.doi.org/10.1201/b12614-2.

Dias, F. J. E., São Clemente, S. C., Pinto, R. M., \& Knoff, M. (2011). Anisakidae nematodes and Trypanorhyncha cestodes of hygienic importance infecting the king mackerel Scomberomorus cavalla (Osteichthyes: Scombridae) in Brazil. Veterinary Parasitology, 175(3-4), 351-355. http://dx.doi.org/10.1016/j.vetpar.2010.10.014. PMid:21115292.

Felizardo, N. N., Knoff, M., Pinto, R. M., \& Gomes, D. C. (2009). Larval anisakid nematodes of the flounder, Paralichthys isosceles Jordan, 1890 (Pisces: Teleostei) from Brazil. Neotropical Helminthology, 3(2), 57-64.

Felizardo, N. N., Torres, E. J. L., Fonseca, M. C. G., Pinto, R. M., Gomes, D. C., \& Knoff, M. (2010). Cestodes of the flounder Paralichthys isosceles Jordan, 1890 (Osteichthyes-Paralichthyidae) from the State of Rio de Janeiro, Brazil. Neotropical Helminthology, 4(2), 113-125.

Fonseca, M. C. G., Knoff, M., Felizardo, N. N., Di Azevedo, M. I. N., Torres, E. J. L., Gomes, D. C., Iñiguez, A. M., \& São Clemente, S. C. (2016). Integrative taxonomy of Anisakidae and Raphidascarididae (Nematoda) in Paralichthys patagonicus and Xystreurys rasile (Pisces: Teleostei) from Brazil. International Journal of Food Microbiology, 235(1), 113-124. http://dx.doi.org/10.1016/j.ijfoodmicro.2016.07.026. PMid:27491056.

Fontenelle, G., Knoff, M., Felizardo, N. N., Torres, E. J., Lopes, L. M., Gomes, D. C., \& Clemente, S. C. (2015). Anisakidae and
Raphidascarididae larvae parasitizing Selene setapinnis (Mitchill, 1815) in the state of Rio de Janeiro, Brasil. Revista Brasileira de Parasitologia Veterinária, 24(1), 72-77. http://dx.doi.org/10.1590/ S1984-29612015010. PMid:25909256.

Fontenelle, G., Knoff, M., Verícimo, M. A., \& São Clemente, S. C. (2018). Epicutaneous sensitization with nematode antigens of fish parasites results in the production of specific IgG and IgE. Journal of Helminthology, 92(4), 403-409. http://dx.doi.org/10.1017/ S0022149X17000633. PMid:28780914.

Knoff, M., \& Gomes, D. C. (2012). Metodologia básica para coleta e processamento de helmintos parasitos. In E. M. Molinaro, L. F. G. Caputo, \& M. R. R. Amendoeira (Eds.), Conceitos e métodos para formação de profissionais em laboratório de saúde (vol. 5, cap. 3, pp. 251-281). Rio de Janeiro: Escola Politécnica de Saúde Joaquim Venâncio, Fiocruz.

Knoff, M., Carmona De São Clemente, S., Gonçalves Da Fonseca, M. C., Del Giudice De Andrada, C., Do Espírito Santo Padovani, R., \& Correa Gomes, D. (2007). Anisakidae parasitos de congro-rosa, Genypterus brasiliensis Regan, 1903 comercializados no estado do Rio de Janeiro, Brasil de interesse na saúde pública. Parasitología Latinoamericana, 62(3), 127-133. http://dx.doi.org/10.4067/S071777122007000200005 .

Knoff, M., Felizardo, N. N., Iñiguez, A. M., Maldonado, A. Jr, Torres, E. J. L., Pinto, R. M., \& Gomes, D. C. (2012). Genetic and morphological characterisation of new species of the genus Hysterothylacium (Nematoda) from Paralichthys isosceles Jordan, 1890 (Pisces: Teleostei) of the Neotropical region, State of Rio de Janeiro, Brazil. Memorias do Instituto Oswaldo Cruz, 107(2), 186-193. http://dx.doi.org/10.1590/ S0074-02762012000200006. PMid:22415256.

Luque, J. L., \& Poulin, R. (2004). Use of fish as intermediate hosts by helminth parasites. Acta Parasitologica, 49(4), 353-361.

Luque, J. L., \& Tavares, L. E. R. (2006). Sistemática, biologia e importância em saúde coletiva de larvas de Anisakidae (Nematoda: Ascaridoidea) parasitas de peixes ósseos marinhos do Estado do Rio de Janeiro, Brasil. In A. T. Silva-Souza (Org.), Sanidade de organismos aquáticos no Brasil (pp. 297-328). Maringá: Abrapoa.

Mattos, D. P. B. G., Verícimo, M. A., Lopes, L. M. S., \& São Clemente, S. C. (2015). Immunogenic activity of the fish tapeworm Pterobothrium heteracanthum (Trypanorhyncha: Pterobothriidae) in BALB/c mice. Journal of Helminthology, 89(2), 203-207. http://dx.doi.org/10.1017/ S0022149X13000795. PMid:24299909.

Menoret, A., \& Ivanov, V. (2009). New name for Progrillotia dollfusi Carvajal et Rego, 1983 (Cestoda: Trypanorhyncha): description of adults from Squatina guggenheim (Chondrichthyes: Squatiniformes) off the coast of Argentina. Folia Parasitologica, 56(4), 284-294. http:// dx.doi.org/10.14411/fp.2009.033. PMid:20128241.

Oliveira, J. V. F., Kuraiem, B. P., Fonseca, M. C. G., Gomes, D. C., \& Knoff, M. (2019). Trypanorhynch cestodes parasitizing Mugil liza (Mugiliformes: Mugilidae) commercialized in the state of Rio de Janeiro, Brazil. Revista Brasileira de Parasitologia Veterinária, 28(4), 773-778. http://dx.doi.org/10.1590/s1984-29612019039. PMid:31365718.

Palm, H. W. (2004). The Trypanorhyncha Diesing, 1863. Bogor: PKSPLIPB Press.

Ribeiro, J., Knoff, M., Felizardo, N. N., Vericimo, M. A., \& Clemente, S. C. S. (2017). Resposta imunológica a antígenos de Hysterothylacium deardorffoverstreetorum de peixes teleósteos. Arquivo Brasileiro de Medicina Veterinária e Zootecnia, 69(2), 422-428. http://dx.doi. org/10.1590/1678-4162-9383.

São Clemente, S. C., Silva, C. M., \& Gottschelk, S. (1997). Prevalência e intensidade de infecção de cestoides Trypanorhyncha em anchovas, 
Pomatomus saltatrix (L.) do litoral do Rio de Janeiro, Brasil. Parasitología al Día, 21(1-2), 54-57.

Spalding, M. D., Fox, H. E., Allen, G. R., Davidson, N., Ferdaña, Z. A., Finlayson, M., Halpern, B. S., Jorge, M. A., Lombana, A., Lourie, S. A., Martin, K. D., McManus, E., Molnar, J., Recchia, C. A., \& Robertson, J. (2007). Marine ecoregions of the world: a bioregionalization of coastal and shelf areas. Bioscience, 57(7), 573-583. http://dx.doi. org/10.1641/B570707.

Yagi, K., Nagasawa, K., Ishikura, H., Nakagawa, A., Sato, N., Kikuchi, K., \& Ishikura, H. (1996). Female worm Hysterothylacium aduncum excreted from human: a case report. Japanese Journal of Parasitology, 45(1), 12-23. 